\title{
Design of a microfluidic chip consisting of micropillars and its use for the enrichment of nasopharyngeal cancer cells
}

\author{
WEN-XUE CHEN ${ }^{1}$, JIN-GAO LI ${ }^{2}$, XIANG-HUI WAN ${ }^{1}$, XUE-SEN ZOU ${ }^{1}$, SHU-YI QI ${ }^{1}$, YU-QING ZHANG ${ }^{1}$, \\ QIU-MIN WENG ${ }^{2}$, JUN-YU LI ${ }^{2}$, WEN-MIN XIONG ${ }^{2}$, CHEN XIE $^{2}$ and WEI-LIANG CHENG \\ Departments of ${ }^{1}$ Clinical Laboratory and ${ }^{2}$ Radiotherapy, Jiangxi Cancer Hospital, Nanchang, \\ Jiangxi 330029; ${ }^{3}$ Jiangxi Railway Health Supervision Institute, Nanchang, Jiangxi 330003, P.R. China
}

Received March 6, 2018; Accepted November 20, 2018

DOI: $10.3892 / \mathrm{ol} .2018 .9771$

\begin{abstract}
The aim of the present study was to discuss the design of a microfluidic chip consisting of columns, and its use for the enrichment of nasopharyngeal cancer (NPC) cells. A microfluidic chip experiment was simulated using FLUENT software. Within the microfluidic chip, aptamers were bound to the reaction chamber (consisting of columns) using a biotin-avidin system. Cell suspension was introduced into the reaction chamber to capture NPC cells. NPC cells were subsequently eluted, and the capture rate of the cells was calculated. The modified aptamer-bound microfluidic chip was able to capture NPC cells with a capture rate of $\sim 90 \%$. The modified aptamer-bound microfluidic chip has a wide range of potential applications for the diagnosis of NPC.
\end{abstract}

\section{Introduction}

Nasopharyngeal cancer (NPC) is one of the most common cancer types in South China. In the early stages of the disease, NPC is usually asymptomatic, with the majority of patients being diagnosed in the middle or advanced stages. Radiotherapy is the primary treatment for NPC; however, $40-60 \%$ of patients relapse following definitive radiotherapy (1-5). Relapse primarily occurs locally, in the neck region, or a combination of the two. The majority of relapse cases appear between 2 and 3 years after radiotherapy.

Relapse and metastasis of NPC are direct causes of mortality. Radiological examination is the major method of detecting relapse and metastasis. However, in order to be visualized radiologically, lymph node lesions resulting from relapse and metastasis must reach a maximum diameter

Correspondence to: Professor Wei-Liang Cheng, Jiangxi Railway Health Supervision Institute, 115 Square South Road, Nanchang, Jiangxi 330003, P.R. China

E-mail: zhuangfc_07@163.com

Key words: nasopharyngeal cancer, microfluidic chip consisting of columns, aptamer of $0.8 \mathrm{~cm}$, according to the Union of International Cancer Control (6), at which point the chance of successful treatment begins to decrease (7). Preceding relapse and metastasis, tumour cells gain access to the peripheral blood, where they are referred to as circulating tumour cells (CTCs) (8). Tumour burden is directly associated with the number of CTCs in the blood; therefore, tumour status may be determined by CTC detection (9).

Aptamers are oligonucleotide or peptide molecules, which, through their unique secondary structure, bind to a specific target molecule (10). Aptamers may be screened using the Systematic Evolution of Ligands by Exponential Enrichment technique, and due to ease of synthesis, storage and transportation, have been employed in an extensive number of applications (11). Microfluidic chips contain complex fluids that are manipulated, observed, detected and controlled at the micron level. In the present study, the microfluidic reaction chamber of a chip was modified for the incorporation of an array of bypass columns. This design increased the area/volume ratio of the fluid environment, thus increasing the reaction efficiency of the microfluidic chip $(12,13)$. Aptamers targeting NPC cell markers were prepared in a preliminary study (14) and subsequently affixed to the inner wall of the reaction chamber within the microfluidic chip. This modified aptamer-bound microfluidic chip is capable of capturing NPC cells from peripheral blood, for the non-invasive diagnosis of NPC.

\section{Materials and methods}

Modelling of an array of bypass columns in the microfluidic chip. The shape, arrangement and length of each major axis of the bypass column were simulated using Fluent 6.3.26 software (ANSYS, Inc., Canonsburg, PA, USA). Alterations in the magnitude of shear force and flow rate were analysed in the microarray. The columns were designed with a circular, elliptical (ratio of major axis to minor axis, 10:7) or square form, and arranged in either an aligned or staggered fashion. Flow rates between 10 and 2,000 $\mu \mathrm{m} / \mathrm{sec}$ were employed. Multiple arrays of bypass columns were simulated using the finite element method (FEM) (15). The microarray with optimal performance was selected for preparation. 
Preparation of the microfluidic chip. The polydimethylsiloxane (PDMS) microfluidic chip was manufactured by Suzhou Wenhao Chip Technology Co., Ltd. (Suzhou, China). The SU-8 mould was prepared via a photolithographic process $(16,17)$, while the PDMS array and cover slips were prepared by PDMS demoulding technology. The typical final step in preparing a closed chip for microfluidic experiments was accomplished using the bonding process $(18,19)$. The chip was composed of an inlet, reaction chamber and an outlet; the reaction chamber was designed with an array of circular bypass columns in a staggered arrangement. The diameter of the bypass columns was $40 \mu \mathrm{m}$, and the spacing between columns was $100 \mu \mathrm{m}$.

Modification of the inner wall of the microfluidic chip. Biotin-labelled aptamers (Sangon Biotech Co., Ltd., Shanghai) were bound to the inner wall of the reaction chamber of the microfluidic chip using a two-step approach, firstly by binding the avidin (Thermo Fisher Scientific, Inc.) through physical absorption to the inner wall of the reaction chamber, followed by the immobilization of the biotin-labelled aptamers to the inner wall of the reaction chamber using the biotin-avidin mechanism. Avidin is a glycoprotein and each avidin molecule consists of four subunits and each subunit can bind to one biotin molecule. Immobilization of the aptamers to the inner wall of the reaction chamber was determined using fluorescence microscopy (magnification, $\mathrm{x} 400$ ).

Aptamer synthesis and buffers. Aptamers were synthesized by Takara Biotechnology Co., Ltd., (Dalian, China). The aptamer sequence is as follows: Fluorescein isothiocyanate-5'-ACC GACCGTGCTGGACTCTACCGCGCAGTGAGGTGAGTG GGGTAGGTTGTTACGTTTCCAGTATGAGCGAGCGTT GCG-3'-Biotin. Buffers used in this study included elution buffer (DPBS containing $4.5 \mathrm{~g} / 1$ glucose and $5 \mathrm{mM} \mathrm{MgCl} \mathrm{M}_{2}$ ), binding buffer (washing buffer containing $0.1 \mathrm{mg} / \mathrm{ml}$ yeast tRNA and $1 \mathrm{mg}$ bovine serum albumin), and capture buffer (binding buffer and Histopaque-1119 from Sigma-Aldrich; Merck KGaA, Darmstadt, Germany) at a 1:1 ratio).

Cell culture. The NPC cell line C666, used to screen aptamer in the present study, human gastric cancer cell line SGC7901, human colorectal cancer cell line HT29, human ovarian cancer cell line SKOV3, human cervical cancer cell line Hela, and normal nasopharyngeal epithelial cell line NP69 were preserved at our laboratory. Keratinocyte-serum-free medium (SFM), 1640 medium, and foetal bovine serum (FBS) were purchased from Gibco (Thermo Fisher Scientific, Inc.). C666, SGC7901, HT29, A549, SKOV3 and HeLa cells were cultured in 1640 medium containing 10\% heat-inactivated FBS and $100 \mathrm{U} / \mathrm{ml}$ penicillin-streptomycin. NP69 cells were cultured in keratinocyte-SFM. All cells were washed twice with Dulbecco's phosphate-buffered saline (DPBS) and treated with $0.25 \%$ trypsin. Following trypsinization, the cells were either harvested or routine passage was performed.

Cell capture experiment. Prior to cell capture, the concentration of the cell suspension was adjusted to $10^{6}$ cells $/ \mathrm{ml}$, and cells were stained with Vybrant DiI or DiD dye (Thermo Fisher Scientific, Inc., Waltham, MA, USA). Staining was performed at $37^{\circ} \mathrm{C}$ for $5 \mathrm{~min}$ according to the manufacturer's protocol.
The cells were rinsed once with wash buffer and resuspended in capture buffer. The cell concentration was adjusted to $10^{6}$ cells $/ \mathrm{ml}$, and the solution was kept on ice prior to use.

The microfluidic chip was treated with $1 \mathrm{mg} / \mathrm{ml}$ avidin for 1 min and washed three times with binding buffer. After incubating the chip in $30 \mu \mathrm{M}$ of biotin-labelled aptamers for $1 \mathrm{~min}$, the chip was again washed three times with binding buffer. Finally, $1 \mathrm{ml}$ of cell suspension (C666 and NP69) was prepared using capture buffer, and injected into the microfluidic chip using a micro-pump. To elute the target cells, the chip was washed three times with binding buffer. To verify the capture efficiency of the modified microfluidic chip, a flat microfluidic chip was constructed and the capture of target cells for the two methods was compared by t-test $(n=4)$.

Separation of tumour cells from whole blood. Whole blood samples $(7.5 \mathrm{ml})$ were collected from healthy volunteers and combined with an EDTA anticoagulant. Physical absorption and aptamer immobilization were performed as described above. Avidin were bound to the inner wall of the reaction chamber by physical absorption, followed by the immobilization of the biotin-labelled aptamers to the inner wall of the reaction chamber. To prevent cell loss during trypsinisation, NPC cells were treated with enzyme-free cell dissociation solution, and subsequently added to the whole blood of the healthy volunteers. The NPC cells from the whole blood samples were captured by the microfluidic chip; the final concentrations of NPC cells were 10, 100, 1,000, and 10,000 cells $/ \mathrm{ml}$, and each test was performed in triplicate.

Capture of NPC cells. Whole blood samples containing a C666 cell suspension or NP69, SGC7901, HT29, SKOV3 and Hela cells were transported to the reaction chamber via the inlet of the microfluidic device. The outlet of the reaction chamber was connected to a cell harvester. To avoid introducing variation into the whole blood samples, no buffer was added during cell separation. A micro-magnetic stirrer was placed near the inlet and outlet to prevent the cell aggregation and ensure uniform distribution within the sample.

Statistical analysis. The shear force within different column types, fluid flow rate and length of the major axis was analysed by independent sample t-test for two-group comparison, and by analysis of variance (ANOVA) using the least significant difference, Bonferroni and Dunnett's T3 post hoc accordingly, for the comparison of more than two groups. The purity of captured cells and the capture efficiency at different lengths of the major axis and flow rate were determined by Pearson correlation analysis. The difference in capture efficiency between the ordinary and the modified microfluidic chip was analysed by t-test. To confirm the association of input and capture of microfluidic chip, the correlation of cell number of input and capture were analysed by Pearson correlation analysis. All data were anlyzed by SPSS 20.0 (IBM Corp., Armonk, NY, USA). $\mathrm{P}<0.05$ was considered to indicate a statistically significant.

\section{Results}

Effects of different parameters on bypass column efficiency. Different arrays of bypass columns were simulated using Fluent software. The impact of column shape and fluid flow rate on 

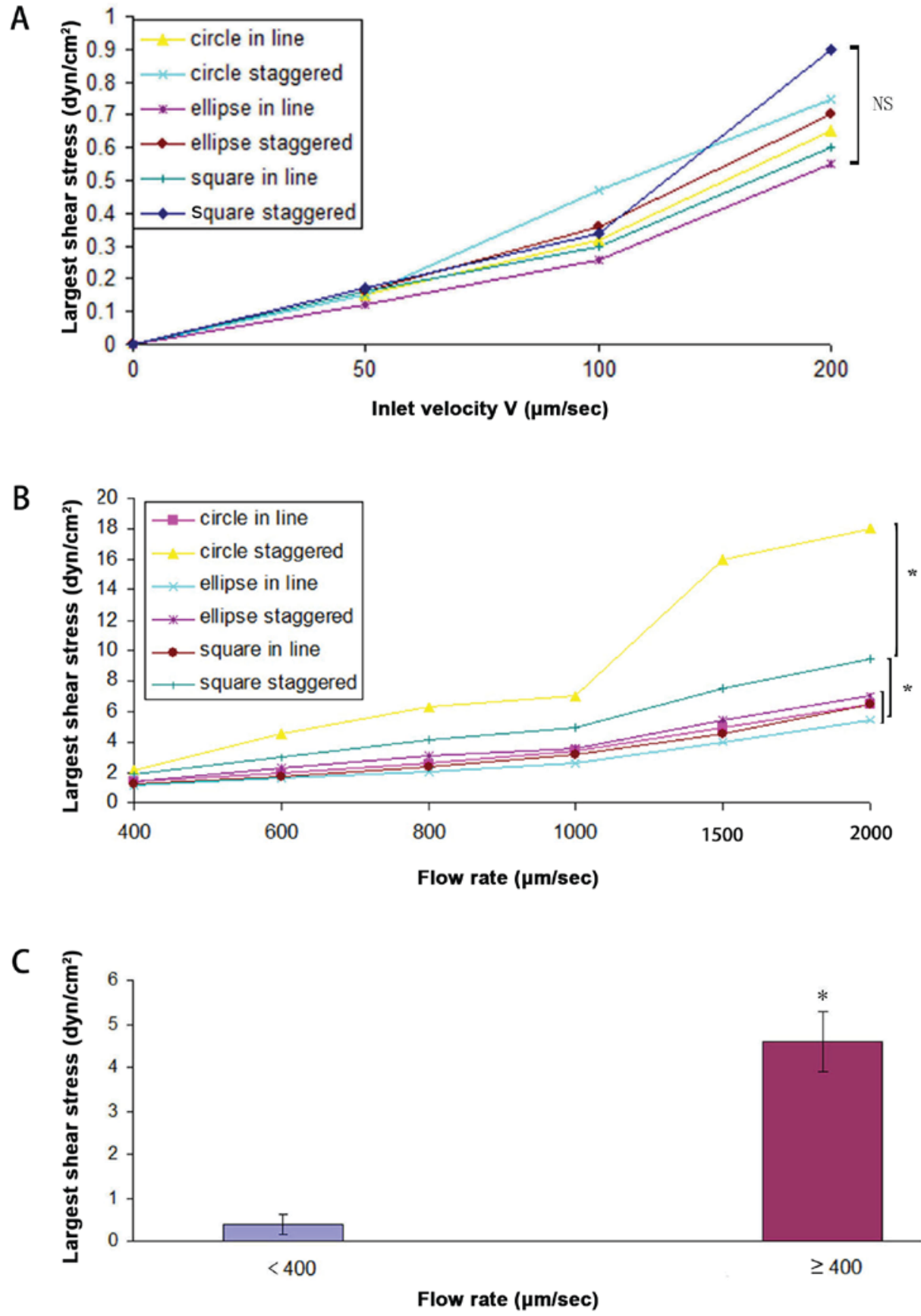

Figure 1. Effect of flow rate at the inlet on the maximum shear force of the array. The maximum shear forces at numerous flow rates and column shapes were assessed for a staggered arrangement and in-line arrangement of columns ( $\mathrm{n}=3$ ). The maximum shear forces at (A) 50-200 $\mu \mathrm{m} / \mathrm{sec}$ and (B) $400-2,000 \mu \mathrm{m} / \mathrm{sec}$ flow rate. (C) The shear forces of flow rate $<400$ and $\geq 400 \mu \mathrm{m} / \mathrm{sec}$. "P $<0.05$ compared with the circle in line, ellipse in line, ellipse staggered, square staggered and circle staggered.

the flow of NPC cells was examined. The fluid flow rate at the inlet had a considerable impact on the shear force within the micro-chamber. The flow rate was gradually increased, and the maximum shear force in different arrays was compared. As the flow rate near the inlet increased, the maximum shear force also increased (Fig. 1). With a flow rate $<400 \mu \mathrm{m} / \mathrm{sec}$ (50, $100,200 \mu \mathrm{m} / \mathrm{sec})$, no significant difference was observed in the maximum shear force across different arrays by ANOVA (P>0.05; Fig. 1A). At a flow rate $\geq 400 \mu \mathrm{m} / \mathrm{sec}(400,600,800$, $1,000,1,500$ and $2,000 \mu \mathrm{m} / \mathrm{sec}$ ), the shear force significantly differed between circle staggered and circle in line, circle staggered and ellipse in line, circle staggered and ellipse staggered, circle staggered and square in line, circle staggered and square staggered, square staggered and circle in line, square staggered and ellipse in line, square staggered and ellipse staggered, square staggered and square in line, ellipse staggered and ellipse in line, and circle in line and ellipse in line arrangements (Fig. 1B). Maximum shear force was observed for the circle columns in a staggered arrangement, followed by the square columns in a staggered arrangement. The shear force of the elliptical columns in a staggered arrangement did not differ from that of the elliptical columns in an aligned arrangement (as determined by ANOVA). As determined by $\mathrm{t}$-test $(\mathrm{P}<0.05)$, the shear force with flow rate $<400 \mu \mathrm{m} / \mathrm{sec}$ was 


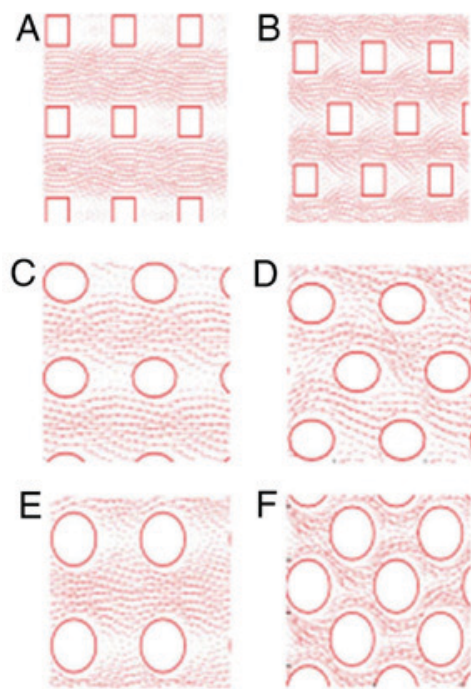

Figure 2. Effect of column arrangement on the fluid flow. (A) Aligned arrangement and (B) staggered arrangement of square columns, (C) aligned arrangement and (D) staggered arrangement of circular columns, (E) aligned arrangement, and (F) staggered arrangement of elliptical columns.

lower compared with that observed for flow rate $\geq 400 \mu \mathrm{m} / \mathrm{sec}$ (Fig. 1C). Murthy et al (20) determined the optimal shear force for the absorption of cells near the micro-columns to be $<9.2 \mathrm{dyn} / \mathrm{cm}^{2}$. At a flow rate of $1,000 \mu \mathrm{m} / \mathrm{sec}$, the maximum shear force was $<9.2 \mathrm{dyn} / \mathrm{cm}^{2}$; however, at $2,000 \mu \mathrm{m} / \mathrm{sec}$, the maximum shear force exceeded $9.2 \mathrm{dyn} / \mathrm{cm}^{2}$ in circle staggered. Therefore, the smallest flow rate of $50 \mu \mathrm{m} / \mathrm{sec}$ was selected and the effect of varying column arrangement on the fluid flow pattern was determined. Fig. 2 illustrates that in an staggered arrangement, the fluid flowed through the centre of the array, and little fluid flowed around the columns. The majority of the fluid was concentrated around the staggered column, the so-called 'flow around the column' phenomenon (21). Therefore, the staggered arrangement was superior to that of the aligned arrangement of columns for fluid flow through the microchip. The major axis of the bypass columns also influences shear force. At a fixed flow rate of $100 \mu \mathrm{m} / \mathrm{sec}$, the effect of major axis length on shear force was examined. Fig. 3 indicates that as the length of the major axis increased, the shear force also increased. When the length of the major axis was $>100 \mu \mathrm{m}(150,200,250$ and $300 \mu \mathrm{m})$, the shear force of square in line was bigger compared with the circle in line, ellipse in line, ellipse staggered, square staggered and circle staggered $(\mathrm{P}<0.05$; Fig. 3A). The shear force of square staggered was bigger compared with the circle in line and ellipse in line arrangements by ANOVA $(\mathrm{P}<0.05)$. When the length of the major axis was $\leq 100 \mu \mathrm{m}$, no significant difference was observed in the maximum shear force across different arrays by ANOVA ( $\mathrm{P}>0.05$; Fig. 3B). As determined by t-test $(\mathrm{P}<0.05)$, the shear force with a major axis length $\leq 100 \mu \mathrm{m}$ was lower compared with that observed for values $>100 \mu \mathrm{m}$ (Fig. 3C). Thus, a major axis length of between 25 and $100 \mu \mathrm{m}$ was selected for the subsequent experiments.

Separation of target cells by microfluidics. Based on the results of the microfluidic chip simulations, a range of $20-45 \mu \mathrm{m}$ was selected as the major axis length for the bypass columns; microfluidic chips were prepared with varying lengths from within this range. The effect of major axis length and inlet flow rate on the capture efficiency and purity of target cells was examined. Fig. 4 illustrates that as the major axis length increased, the purity of captured cells also increased, whilst the capture efficiency decreased. Pearson correlation analysis indicated a significant positive correlation between axis length and the purity of the captured cells $(\mathrm{R}=0.94$; $\mathrm{P}<0.01)$, a significant negative correlation between axis length and the capture efficiency $(\mathrm{R}=-0.95 ; \mathrm{P}<0.01)$, and negative correlation between the capture efficiency and the purity of captured $(R=-0.86$; $\mathrm{P}<0.05)$ at a range of $20-45 \mu \mathrm{m}$ axis length. With the increase of capture efficiency, the purity of capture decreased therefore, the proper long axis was maximum number of cells obtained from colligating capture purity and capture efficiency (input cells $\mathrm{x}$ capture purity $\mathrm{x}$ capture efficiency). When the long axis was $45 \mu \mathrm{m}$, the target cells were captured the most. Therefore, the length of the major axis was set at $45 \mu \mathrm{m}$ and the effect of different flow rates on the capture efficiency and purity of the captured cells were also analysed. Fig. 5 illustrates that as the flow rate increased the capture efficiency decreased, whilst the purity of captured cells increased when the long axis was fixed. A negative correlation was indicated between flow rate and capture efficiency ( $\mathrm{R}=-0.97 ; \mathrm{P}<0.01)$, a positive correlation between flow rate and capture purity $(\mathrm{R}=0.92 ; \mathrm{P}<0.01)$, and a negative correlation between capture efficiency and the capture purity $(\mathrm{R}=-0.92 ; \mathrm{P}<0.01)$. Therefore, the proper flow rate was the maximum number of cells obtained from colligating capture purity and the capture efficiency (input cells $\mathrm{x}$ capture purity $\mathrm{x}$ capture efficiency). At flow rates between 200 and $800 \mu \mathrm{m} / \mathrm{sec}$, the capture efficiency and purity of the captured cells were $>70 \%$. The number of captured target cells was the highest at a flow rate of $700 \mu \mathrm{m} / \mathrm{sec}$; therefore, for subsequent experiments, a major axis length of $45 \mu \mathrm{m}$, and a flow rate of $700 \mu \mathrm{m} / \mathrm{sec}$ were selected. Fig. 6 compares the capture efficiency between a conventional flat channel microfluidic chip and modified version, the microfluidic chip reaction chamber with an array of bypass columns defined as the micropillar channel microfluidic chip. The t-test confirmed that the capture efficiency of the modified microfluidic chip was considerably higher compared with that of the conventional one $(\mathrm{P}<0.01)$.

To verify the enrichment capacity of microfluidic chip for NPC cells, C666 cells, a nasopharyngeal cancer cell line used to screen aptamer in the present study, were used as target cells, and NP69, SGC7901, HT29, SKOV3 and Hela were selected as controls. C666 cells were enriched using a microfluidic chip bound with biotin-labelled aptamers. For $1 \mathrm{ml}$ of cells, a 1:1,000 ratio of target to control cells was sought, at a final concentration of $10^{6}$ cells $/ \mathrm{ml}$. The two cell types were stained prior to the experimentation; C666 cells were prestained with Vybrant DiI dye (red), and NP69, SGC7901, HT29, SKOV3 and Hela were prestained with Vybrant DiD dye (blue). Fig. 7 represents the cell mixture (target cell, C666; control cells, NP69) prior to (Fig. 7A) and following (Fig. 7B) separation of NPC cells using the microfluidic chip. The modified aptamer-bound microfluidic chip effectively enriched NPC cells with a capture efficiency of $92 \%$, the percentage of tumor cells isolated/total tumor cells present. 


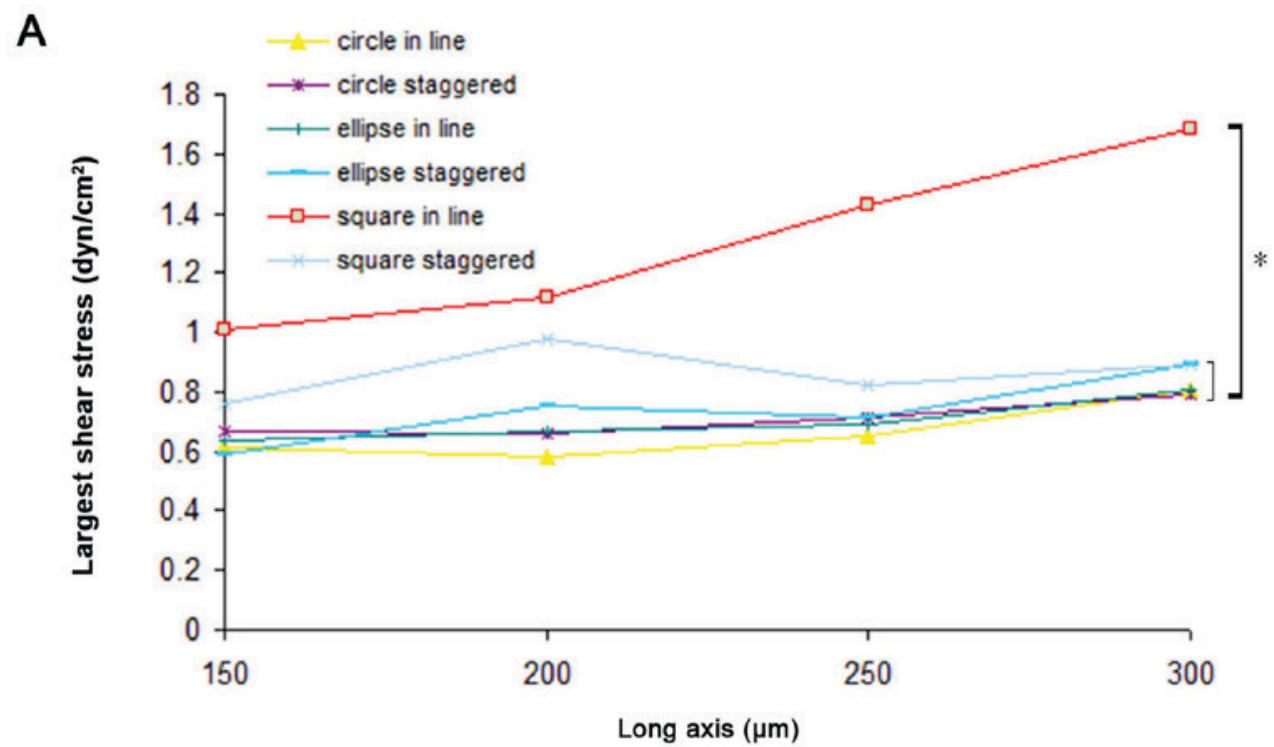

B

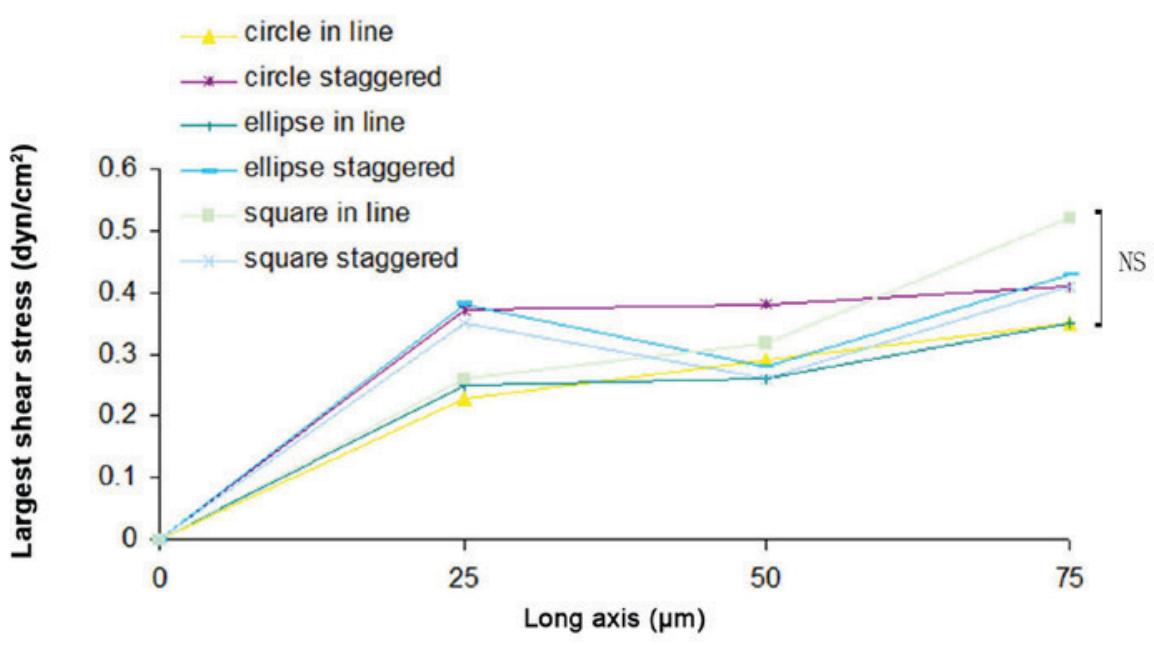

C

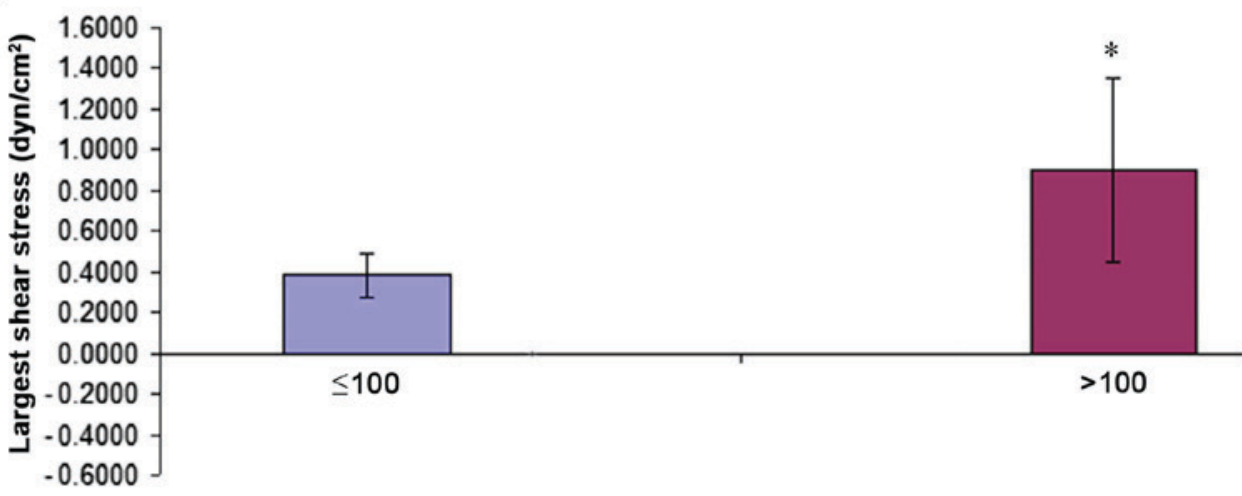

Long axis $(\mu \mathrm{m})$

Figure 3. Effect of major axis length on the maximum shear force of the array. The maximum shear force at numerous lengths of the major axis and column shapes was assessed for a staggered arrangement and in-line arrangement of columns $(\mathrm{n}=3)$. The maximum shear force at (A) $0-75 \mu \mathrm{m}$ axis length and (B) 150-300 $\mu \mathrm{m}$ axis length. (C) The shear forces axis length of $\leq 100$ and $>100 \mu \mathrm{m}$. "P $<0.05$ compared with the circle in line, ellipse in line, ellipse staggered, square staggered and circle staggered.

Separation of NPC cells from whole blood. The addition of cultured NPC cells into peripheral blood samples was used as a model for CTCs in the peripheral blood of tumour patients. Specifically, varying concentrations of C666 cells were added to $1 \mathrm{ml}$ of peripheral blood, and NPC cells were separated and enriched using the microfluidic chip. The capture efficiency for NPC cells from blood samples was $>90 \%$. Fig. 8 indicates that the quantities of captured cells ranged from 10-10,000 with varying concentrations of total NPC cells, and the coefficient of correlation was 0.99 (calculated using linear regression). 


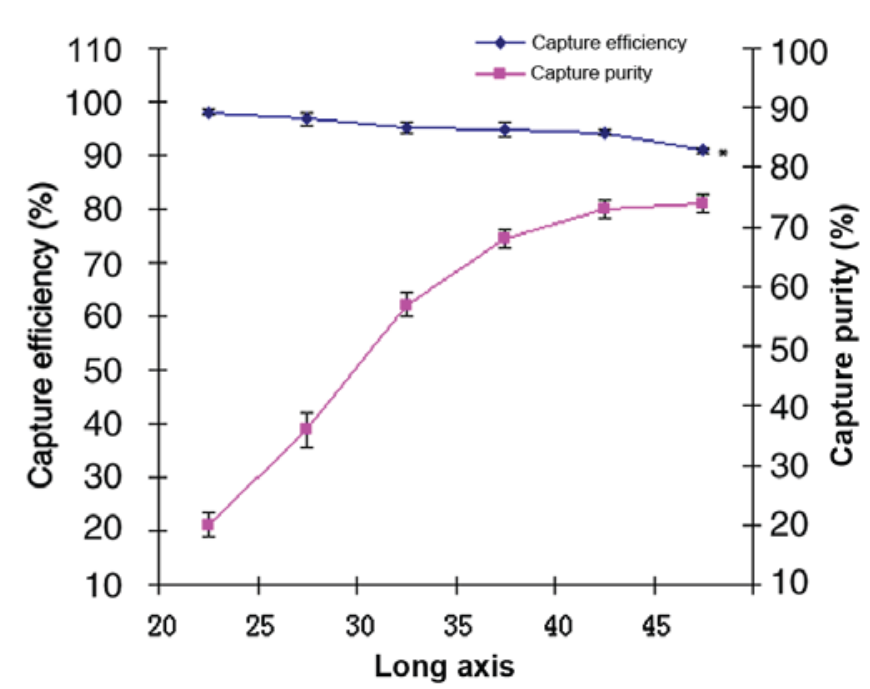

Figure 4. Effect of major axis length on the capture efficiency and purity of captured cells. ${ }^{\text {" }}<<0.05$.

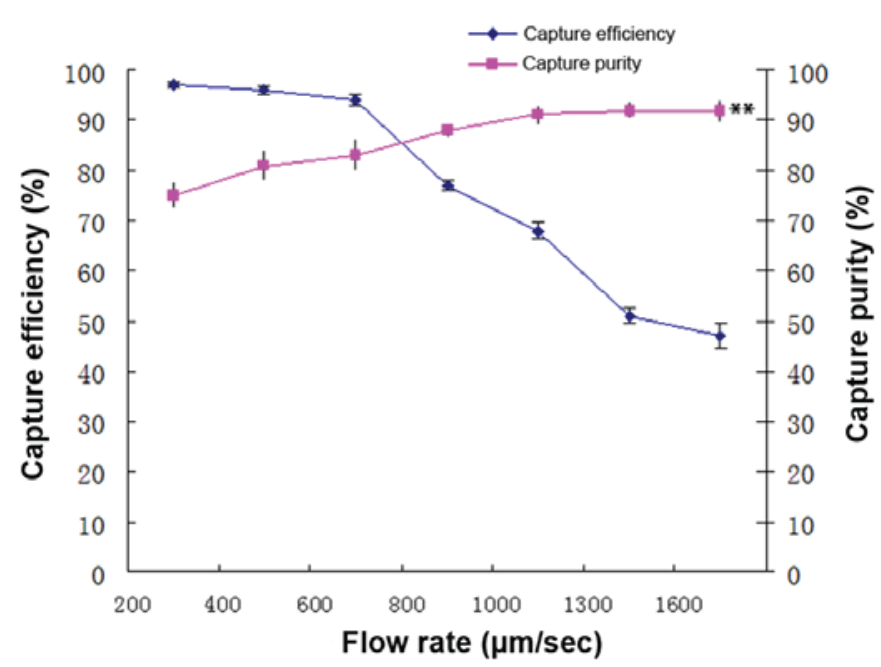

Figure 5. Effect of flow rate on the capture efficiency and purity of captured cells. ${ }^{* *} \mathrm{P}<0.01$. $(\mathrm{n}=3)$.

\section{Discussion}

Liquid biopsy for tumours is currently a prevalent topic in the field of tumour diagnosis and treatment. Tumour cells in the peripheral blood of patients can be detected using different techniques (22). Methods commonly employed for the detection of CTCs include: i) Flow cytometry, used for detecting DNA from eight CTCs in breast cancer; ii) immune-magnetic bead separation; and iii) the CellSearch system (Menarini Silicon Biosystems, Inc., Huntington Valley, PA, USA) developed based on the principle of immune-magnetic bead-based selection (23). The CellSearch system is a semi-automatic CTC detector that binds the epithelial cell adhesion molecule of CTCs to facilitate their separation from peripheral blood cells. It is currently used to determine the prognosis of patients with breast cancer. Additional methods include membrane filtration, which separates tumour cells from the peripheral blood on the basis of size and selected cell markers. The aforementioned techniques (except for DNA detection) use

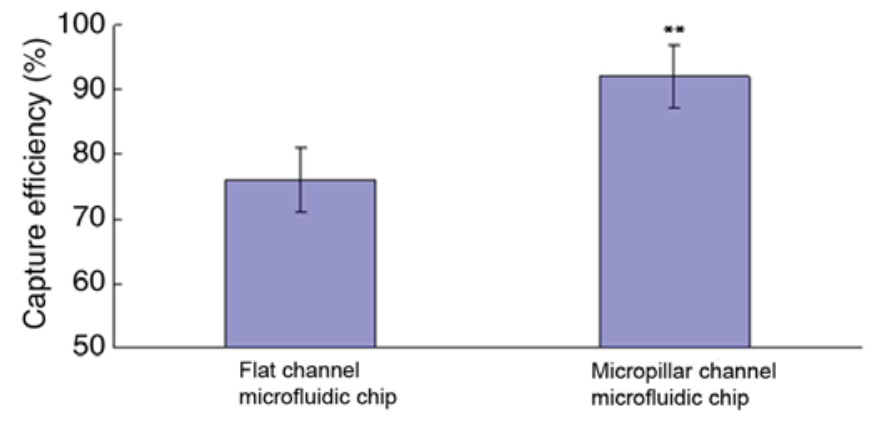

Figure 6. Comparison of the capture efficiency between a conventional flat channel microfluidic chip and modified micropillar channel microfluidic chip (the microfluidic chip reaction chamber with an array of bypass columns defined as micropillar channel microfluidic chip) $(n=4)$. Statistical significance was assessed by t-test. ${ }^{* *} \mathrm{P}<0.01$ vs. flat channel microfluidic chip.
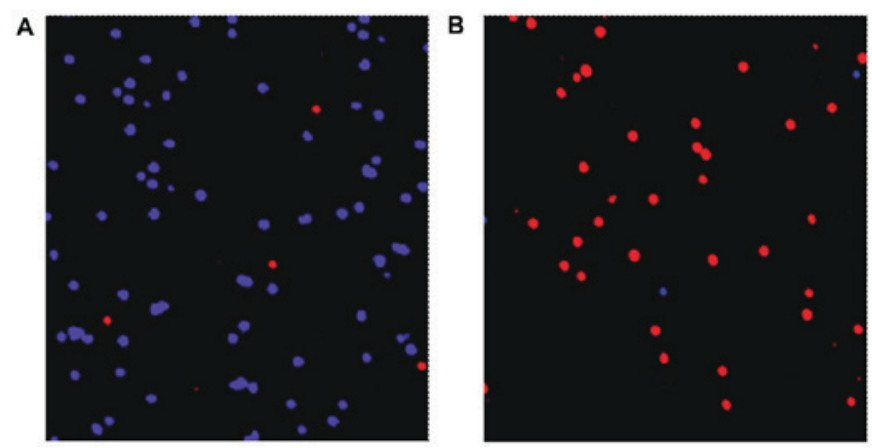

Figure 7. Comparison of cell samples prior to and following enrichment of nasopharyngeal cancer cells with the microfluidic chip. Cells were stained with Vybrant DiI dye (red) and Vybrant DiD dye (blue) (A) Target cells (red) and control cells (blue) prior to sorting; (B) Enrichment of target cells (red) from the cell mixture using the microfluidic chip (magnification, $\mathrm{x} 400$ ).

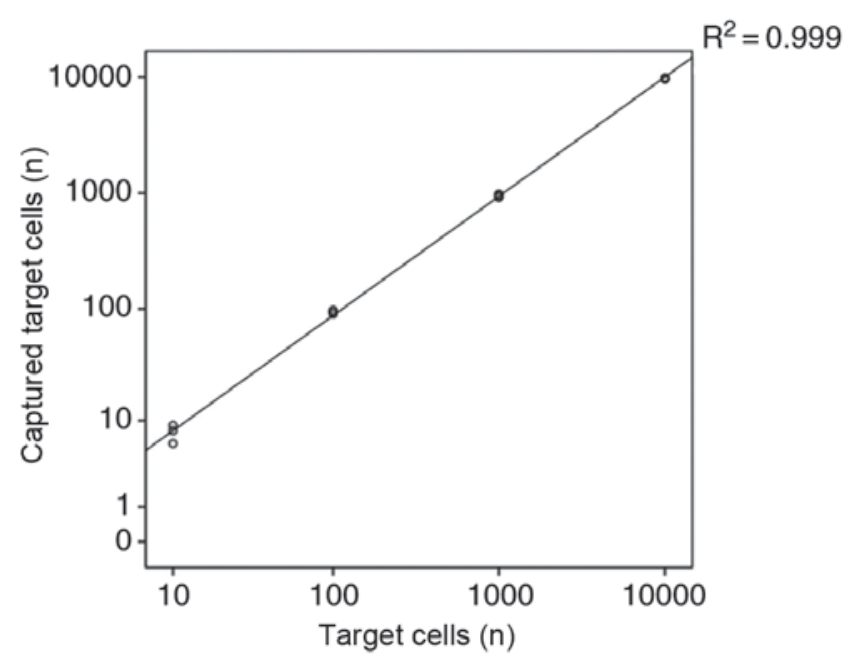

Figure 8. Correlation analysis between total NPC cells in whole blood samples and the nasopharyngeal cancer cells enriched by the microfluidic chip (logarithmic coordinates). $\mathrm{n}=3$. Data analysed by Pearson correlation $\mathrm{P}<0.01$.

high-affinity antibodies to capture and count CTCs (24-26). However, the number of available antibodies that are able to bind to tumour cells or cell lines is limited, and off-target binding remains a major challenge (27). Specific preservation 
conditions are required to maintain the functional activity of protein probes, (the principal limitation of antibody-based capture), which restricts the application of these techniques in tumour detection.

Aptamers not only exhibit higher affinity and specificity compared with antibodies, but are also more easily synthesized, preserved, transported and surface-modified. The use of aptamers for capturing CTCs has been reported in recent years, with capture efficiency varying between 70 and $98 \%(28,29)$. In the present study, a microfluidic chip was modified by incorporating an array of bypass columns into the reaction chamber to increase the contact area between cells and the inner surface of the chamber. Experiments indicated that the capture efficiency of the modified microfluidic chip (90\%) was higher compared with that of a conventional microfluidic chip (78\%). Additionally, the modified aptamer-bound microfluidic chip targeting NPC cellsthat was screened by preliminary research, successfully detected NPC cells in the peripheral blood. The capture efficiency was $90 \%$, higher compared with the reported efficiency in existing studies $(30,31)$.

It was demonstrated that an aptamer-bound microfluidic chip was able to separate NPC cells from whole blood at a higher efficiency than is currently attainable, and neither the aptamer-bound microfluidic chip nor the detected samples required pre-treatment. The method may be performed quickly and with an effective lower limit of 10 cells. The capture efficiency of the aptamer-bound microfluidic chip was determined by preliminary in vitro cell-based experiments, though the true diagnostic value may be verified by clinical patient sample. Additionally, the aptamer of the microfluidic chip may only recognize the corresponding matched epitope, thus may not reliably capture all types of cancer cells. Subsequent research may involve samples from patients with nasopharyngeal cancer with mixed aptamers to capture a greater range of cancer cell types. Despite these limitations, the results of this study implicate far-reaching clinical applications for the modified microfluidic chip.

\section{Acknowledgements}

The authors would like to thank Dr Xuesen Zou from the Departments of Clinical Laboratory, Jiangxi Cancer Hospital for simulation of various parameters of micropillar channel microfluidic chip using Fluent 6.3.26 software in the study.

\section{Funding}

This study was supported by the National Natural Science Foundation (grant no. 81360402), Jiangxi Provincial Nature Fund (grant no. 20142BAB205058), Jiangxi Provincial Natural Science Foundation (grant no. 20151BAB205027), and Jiangxi Province Science and Technology Plan Projects (grant no. 20151BBG70131).

\section{Availability of data and materials}

The datasets used and/or analysed during the current study are available from the corresponding author by reasonable request.

\section{Authors' contributions}

WXC, JGL, XSZ and WLC were responsible for the conception and design of the present study. XHW, SYQ, YQZ, QMW, JYL, WMX and CX were responsible for the experiment. WXC, WLC and XHW assisted in data analysis and interpretation. All authors were involved in the writing of the manuscript. All authors have read and approved the final version of the manuscript.

\section{Ethical approval and consent to participate}

The study was approved by the ethics committee of Jiangxi Cancer Hospital, Nanchang, China. Written informed consent was obtained from all volunteers.

\section{Patient consent for publication}

Written informed consent was obtained from all volunteers.

\section{Competing interests}

The authors declare that they have no conflict of interest.

\section{References}

1. Li JG, Yuan X, Zhang LL, Tang YQ, Liu L, Chen XD, Gong XC, Wan GF, Liao YL, Ye JM and Ao F: A randomized clinical trial comparing prophylactic upper versus whole-neck irradiation in the treatment of patients with node-negative nasopharyngeal carcinoma. Cancer 119: 3170-3176, 2013.

2. Kuo DY, Chang MH, Wang SY, Hsieh PY and Shueng PW: Unusual axillary metastasis of recurrent nasopharyngeal cancer: A case report. Medicine (Baltimore) 96: e6854, 2017.

3. Wang WY, Twu CW, Chen HH, Jiang RS, Wu CT, Liang KL, Shih YT, Chen CC, Lin PJ, Liu YC and Lin JC: Long-term survival analysis of nasopharyngeal carcinoma by plasma Epstein-Barr virus DNA levels. Cancer 119: 963-970, 2013.

4. Lee AW, Lin JC and Ng WT: Current management of nasopharyngeal cancer. Semin Radiat Oncol 22: 233-244, 2012.

5. Yuan C, Xu XH, Luo SW, Wang L, Sun M, Ni LH, Xu L, Wang XL and Zeng G: Which neoadjuvant chemotherapy regimen should be recommended for patients with advanced nasopharyngeal carcinoma?: A network meta-analysis. Medicine (Baltimore) 97: e11978, 2018.

6. OuYang PY, You KY, Zhang LN, Xiao Y, Zhang XM and Xie FY: External validity of a prognostic nomogram for locoregionally advanced nasopharyngeal carcinoma based on the 8th edition of the AJCC/UICC staging system: A retrospective cohort study. Cancer Commun (Lond) 38: 55, 2018.

7. Ren XY, Wen X, Li YQ, Zhang J, He QM, Yang XJ, Tang XR, Wang YQ, Zhang PP, Chen XZ, et al: TIPE3 hypermethylation correlates with worse prognosis and promotes tumor progression in nasopharyngeal carcinoma. J Exp Clin Cancer Res 37: 227, 2018.

8. Tu Q, Wu X, Le Rhun E, Blonski M, Wittwer B, Taillandier L, De Carvalho Bittencourt M and Faure GC: CellSearch technology applied to the detection and quantification of tumor cells in CSF of patients with lung cancer leptomeningeal metastasis. Lung Cancer 90: 352-357, 2015.

9. Sun B, Liu H, Wang S, Xiang J and Liu X: Prognostic impact of circulating tumor cells in patients with ampullary cancer. J Cell Physiol 233: 5014-5022, 2018.

10. Bayat P, Nosrati R, Alibolandi M, Rafatpanah H, Abnous K, Khedri $M$ and Ramezani M: SELEX methods on the road to protein targeting with nucleic acid aptamers. Biochimie 154: 132-155, 2018.

11. Zou Y, Duan N, Wu S, Shen M and Wang Z: Selection, identification, and binding mechanism studies of an ssDNA aptamer targeted to different stages of E. coli O157:H7. J Agric Food Chem 66: 5677-5682, 2018.

12. Filardi V: Carotid artery stenosis near a bifurcation investigated by fluid dynamic analyses. Neuroradiol J 26: 439-453, 2013. 
13. Tian F, Cai L, Chang J, Li S, Liu C, Li T and Sun J: Label-free isolation of rare tumor cells from untreated whole blood by interfacial viscoelastic microfluidics. Lab Chip 18: 3436-3445, 2018.

14. Chen WX, Zhang KH, Zou XS, Chen YQ and Li JG: Screening and identification of the nucleic acid aptamers in nasopharyngeal carcinoma. Genet Mol Res 12: 6850-6857, 2013.

15. Hu C, Munglani G, Vogler H, Ndinyanka Fabrice T, Shamsudhin N, Wittel FK, Ringli C, Grossniklaus U, Herrmann HJ and Nelson BJ: Characterization of size-dependent mechanical properties of tip-growing cells using a lab-on-chip device. Lab Chip 17: 82-90, 2016.

16. Le Gac S, Cren-Olivé C, Rolando C and Arscott S: A novel nib-like design for microfabricated nanospray tips. J Am Soc Mass Spectrom 15: 409-412, 2004.

17. Benlarbi M,Blum LJ and Marquette CA: SU-8-carbon composite as conductive photoresist for biochip applications. Biosens Bioelectron 38: 220-225, 2012.

18. Nuttall LP, Brossard FSF, Lennon SA, Reid BPL, Wu J, Griffiths J and Taylor RA: Optical fabrication and characterisation of SU-8 disk photonic waveguide heterostructure cavities. Opt Express 25: 24615-24622, 2017.

19. Altuna A, Menendez de la Prida L, Bellistri E, Gabriel G, Guimerá A, Berganzo J, Villa R and Fernández LJ: SU-8 based microprobes with integrated planar electrodes for enhanced neural depth recording. Biosens Bioelectron 37: 1-5, 2012.

20. Murthy SK, Sin A, Tompkins RG and Toner M: Effect of flow and surface conditions on human lymphocyte isolation using microfluidic chambers. Langmuir 20: 11649-11655, 2004

21. Oota-Ishigaki A, Masuzawa T and Nagayama K: Analysis of the effect of the size of three-dimensional micro-geometric structures on physical adhesion phenomena using microprint technique. Int J Artif Organs 41: 277-283, 2018.

22. Hille C and Pantel K: Prostate cancer: Circulating tumour cells in prostate cancer. Nat Rev Urol 15: 265-266, 2018.

23. Le UT, Bronsert P, Picardo F, Riethdorf S, Haager B, Rylski B, Czerny M, Beyersdorf F, Wiesemann S, Pantel K, et al: Intraoperative detection of circulating tumor cells in pulmonary venous blood during metastasectomy for colorectal lung metastases. Sci Rep 8: 8751, 2018.
24. Schneck H, Gierke B, Uppenkamp F, Behrens B, Niederacher D, Stoecklein NH, Templin MF, Pawlak M, Fehm T and Neubauer H; Disseminated Cancer Cell Network (DCC Net) Duesseldorf: EpCAM-independent enrichment of circulating tumor cells in metastatic breast cancer. PLoS One 10: e144535, 2015.

25. Wang S, Liu K, Liu J, Yu ZT, Xu X, Zhao L, Lee T, Lee EK, Reiss J, Lee YK, et al: Highly efficient capture of circulating tumor cells by using nanostructured silicon substrates with integrated chaotic micromixers. Angew Chem Int Ed Engl 50: 3084-3088, 2011.

26. Yin C, Wang Y, Ji J, Cai B, Chen H, Yang Z, Wang K, Luo C, Zhang W, Yuan C and Wang F: Molecular profiling of pooled circulating tumor cells from prostate cancer patients using a dual-antibody-functionalized microfluidic device. Anal Chem 90: 3744-3751, 2018.

27. Sun $C$, Zhang $R$, Gao $M$ and Zhang $X$ : A rapid and simple method for efficient capture and accurate discrimination of circulating tumor cells using aptamer conjugated magnetic beads and surface-enhanced Raman scattering imaging. Anal Bioanal Chem 407: 8883-8892, 2015

28. Chiu WJ, Ling TK, Chiang HP, Lin HJ and Huang CC: Monitoring cluster ions derived from aptamer-modified gold nanofilms under laser desorption/ionization for the detection of circulating tumor cells. ACS Appl Mater Interfaces 7: 8622-8630, 2015.

29. Zeng Z, Tung $\mathrm{CH}$ and $\mathrm{Zu} \mathrm{Y:} \mathrm{A} \mathrm{cancer} \mathrm{cell-activatable}$ aptamer-reporter system for one-step assay of circulating tumor cells. Mol Ther Nucleic Acids 3: e184, 2014.

30. Wan Y, Liu Y, Allen PB, Asghar W, Mahmood MA, Tan J, Duhon H, Kim YT, Ellington AD and Iqbal SM: Capture, isolation and release of cancer cells with aptamer-functionalized glass bead array. Lab Chip 12: 4693-4701, 2012.

31. Phillips JA, Xu Y, Xia Z, Fan ZH and Tan W: Enrichment of cancer cells using aptamers immobilized on a microfluidic channel. Anal Chem 81: 1033-1039, 2009.

This work is licensed under a Creative Commons Attribution-NonCommercial-NoDerivatives 4.0 International (CC BY-NC-ND 4.0) License. 